\title{
Ciprofloxacin containing Mannich base and its copper complex induce antitumor activity via different mechanism of action
}

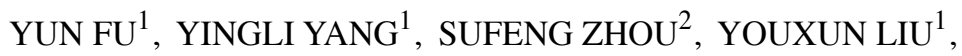 \\ YANBIN YUAN $^{3}$, SHAOSHAN LI ${ }^{3}$ and CHANGZHENG LI ${ }^{1}$ \\ ${ }^{1}$ Department of Molecular Biology and Biochemistry, ${ }^{2}$ Clinical Skill Training Center, \\ Xinxiang Medical University; ${ }^{3}$ Department of Surgery, The Third Affiliated Hospital \\ of Xinxiang Medical University, Xinxiang, Henan, P.R. China
}

Received June 21, 2014; Accepted August 1, 2014

DOI: $10.3892 /$ ijo.2014.2611

\begin{abstract}
The Mannich base containing ciprofloxacin and kojic acid structural units was prepared and evaluated in antitumor activity. The enhancement in antitumor activity was observed both from the Mannich base $\left(\mathrm{IC}_{50}: 103.3 \pm 5.0 \mu \mathrm{M}\right.$ for HepG2, 87.9 $\pm 8.0 \mu \mathrm{M}$ for HCT-116 cell) and its copper complex $\left(\mathrm{IC}_{50}: 11.5 \pm 1.8 \mu \mathrm{M}\right.$ for HepG2, 44.4 $\pm 2.5 \mu \mathrm{M}$ for HCT-116 cell) compared to the ciprofloxacin and kojic acid. The mechanistic studies via RT-PCR, cell cycle analysis, mitochondrial membrane potential measurement, inhibition of topoisomerase and molecular docking indicated that there is a different molecular mechanism between the Mannich base and its copper complex. The cytotoxicity of the Mannich base was involved in apoptosis, cell cycle arrest, depolarization of mitochondrial membrane and weaker topoisomerase II inhibition, but the copper complex exerted its cytotoxicity mainly through dual topoisomerase inhibition, especially stabilizing the intermediate of cleavage DNA-topoisomerase complex.
\end{abstract}

\section{Introduction}

Kojic acid (5-hydroxy-2-hydroxymethyl-4H-pyran-4-one) is a biologically important natural product and used widely as an additive in the food industry and bleaching agent in cosmetic preparations (1). Kojic acid and its derivatives also possess other various bioactivities such as antimicrobial $(2,3)$, anti-

Correspondence to: Dr Changzheng Li, Department of Molecular Biology and Biochemistry, Xinxiang Medical University, East 601 Jinsui Road, Xinxiang, Henan, P.R. China

E-mail: changzhenl@yahoo.com

Dr Shaoshan Li, Department of Surgery, Third University Hospital, Xinxiang Medical University, East 601 Jinsui Road, Xinxiang, Henan, P.R. China

E-mail: shaoshanlioo1@sina.com

Key words: ciprofloxacin derivative, kojic acid derivative, antitumor activity, Mannich base, topoisomerase inhibition, copper complex diabetic (4) and antitumor activity (5). Moreover, it can chelate many metal ions as bidentate ligand, such copper (6) and its skin lightening ability is stemmed from its copper-chelating property. Copper chelation is currently being investigated as an antiangiogenic and antineoplastic agent in patients diagnosed with esophageal carcinoma, hormone-refractory prostate cancer, colorectal cancer, and breast cancer (7). In light of its copper-chelating property with tyrosinase, kojic acid appears to be a potential candidate to develop novel classes of metal-chelating antiproliferative agents (8), and many of its derivatives of it have been synthesized to improve their biological activity $(9,10)$.

The fluoroquinolones belong to the group of synthetic antibiotics that exert broad-spectrum antimicrobial activities. Ciprofloxacin is one of the fluoroquinolones and widely used in clinic as antimicrobial agent. In addition to antimicrobial activity, antitumor activity against colon cancer, bladder cancer, leukemia and hepatic cell lines have been found and linked to topoisomerase II (Top II) inhibitory (11-13). The structure-activity relationship (SAR) and the functions of different positions on the quinolone core have been identified (14). The SAR studies indicated that the group at position 7 affects its antibacterial spectrum (15). The substituted 7-piperazinyl derivatives of ciprofloxacin, such as azo (11), Mannich base $(16,17), \mathrm{N}$-alkylated (18) and $\mathrm{N}$-acylated ciprofloxacin derivatives (19) have been synthesized and evaluated for antibacterial activity.

Combined multifunctional units into a molecule is a strategy of fragment-based drug discovery to find lead compounds for different research aims, the Mannich reaction is one of ways used to perform this task. In addition, the Mannich bases themselves have good biological activity, so many of these compounds were synthesized and investigated for antimicrobial and antitumor activities. In our previous investigation (13), we found that the structural modification on ciprofloxacin may improve its antitumor activity, as extended study, the compound of 7-piperazinyl ciprofloxacin with kojic acid and its copper complex were synthesized in order to investigate whether there is potent enhancement in antitumor activities. In this study, the potent molecular mechanism of action of the Mannich base and its copper complex was explored via RT-PCR, cell cycle analysis, topoisomerase inhibition and 
molecular docking, revealing a new action mechanism for the copper complex.

\section{Materials and methods}

Materials. All chemical reagents were analytical reagent grade. MTT, rhodamine 123, propidium iodide, ethidium bromide and SDS were purchased from Sigma-Aldrich, Inc. (Shanghai, China). Ciprofloxacin hydrochloride was obtained from Sangon Biotech (Shanghai, China). Kojic acid was purchased from Aladdin Industrial Corp. (Shanghai, China).

Preparation of Mannich base of kojic acid with ciprofloxacin . Mannich bases were prepared by the reaction of ciprofloxacin $(0.01 \mathrm{~mol})$ and kojic acid $(0.01 \mathrm{~mol})$ in methanol with $37 \%$ formalin $(0.012 \mathrm{~mol})$. The mixture was stirred vigorously for $4 \mathrm{~h}$. The resulting precipitate was collected by filtration and washed with cold methanol. The crude product was recrystallized from methanol. The Mannich base was characterized by ${ }^{1} \mathrm{H}$ NMR (400 MHz, Bruker, Switzerland) spectrum and Mass spectrum: ${ }^{1} \mathrm{H}$ NMR (d6-DMSO) ${ }^{1} \mathrm{H}$ NMR d (DMSO-d6, $400 \mathrm{MHz})^{\delta}$ (ppm): 2.61 (4H; t; piperazine), 3.35 (4H; s; piperazine), 3.58 (2H; s; - $\left.\mathrm{CH}_{2}-\right), 4.34\left(2 \mathrm{H}\right.$; s; $\left.-\mathrm{HOCH}_{2}-\right), 5.77(1 \mathrm{H}$; t; $\left.\mathrm{CH}_{2}-\mathrm{OH}\right), 6.38$ (1H; s; H5-pyran), 9.45 ppm $(1 \mathrm{H} ; \mathrm{s} ; 3-\mathrm{OH}$ pyran), 1.18 - $1.32\left(\mathrm{~m}, 4 \mathrm{H},-\mathrm{CH}_{2} \mathrm{CH}_{2}-\right), 3.16-3.24(\mathrm{~m}, 8 \mathrm{H}$, piperazine-H), $3.35(\mathrm{~m}, 1 \mathrm{H}, \mathrm{CH}), 7.58\left(\mathrm{~d}, 1 \mathrm{H}, \mathrm{J}=7.2 \mathrm{~Hz}, \mathrm{H}_{8}\right.$ of cip), 7.89 (d, J = $13.5 \mathrm{~Hz}, 1 \mathrm{H}, \mathrm{H}_{5}$ of cip), 8.66 (s, 1H, $\mathrm{H}_{2}$ of cip), 15.16 (s, 1H, -COOH); MS (VG Autospec-3000 spectrometer, Micromass, UK): m/e 485.46. The structure of the Mannich base and its copper complex are shown in Fig. 1.

Cell culture and cytotoxicity assay. HCT-116 and HepG2 human hepatoma cell lines (Y-S Biotechnology Inc., Shanghai, China) were propagated continuously in RPMI-1640 medium supplemented with $10 \%$ freshly inactivated fetal calf serum and antibiotics $(100 \mathrm{U} / \mathrm{ml}$ penicillin $\mathrm{G}$, and $100 \mu \mathrm{g} / \mathrm{ml}$ streptomycin) in a humidified atmosphere of $5 \% \mathrm{CO}_{2}$ and $95 \%$ air at $37^{\circ} \mathrm{C}$. The HCT-116 and HepG2 cells in exponential-phase were detached by $0.25 \%$ trypsin, followed by centrifugation, PBS washing, and re-suspended in RPMI-1640, then the equal cells were seeded $\left(5 \times 10^{3} /\right.$ well) into a 96 -well plate. When the cells attached to the Mannich base the copper complex was added at the final concentrations at 200, 100, 50, 25, 12.5, 6,3 and $1.5 \mu \mathrm{M}$ which varied with the drug and cell line. After incubation for $48 \mathrm{~h}, 10 \mu \mathrm{l}$ MTT solution $(1 \mathrm{mg} / \mathrm{ml})$ was added to each well, the plate was further incubated for $4 \mathrm{~h}$. The cell culture was removed by aspiration and $100 \mu 1$ DMSO was added into each well to dissolve the formazan crystals. The measurement of absorbance at $570 \mathrm{~nm}$ was performed on an ELISA spectrophotometer (MK3, Thermo Scientific, Shanghai, China). Percent growth inhibition was defined as percent absorbance inhibition within appropriate absorbance in each cell line. The same assay was done in triplet.

$R T-P C R$. Total RNA was extracted from the HepG2 cells using TRIzol reagent (Shangong Biological, Shanghai, China) according to the manufacturer's protocol. Three micrograms of total RNA were used for reverse transcription in a total volume of $20 \mu \mathrm{l}$ following the manufacturer's recommendation (Lifefeng, Shanghai, China). Aliquots of $2 \mu \mathrm{l}$ cDNA were subsequently amplified in a total volume of $25 \mu$ l. The sense and antisense primer for $\beta$-actin were 5'-ACACTGTGCC CATCTACGAGG-3' and 5'-CGGACTCGTCATACTCC TGCT-3' (615 bp) that were used as an internal control; the sense and antisense primers for bcl 2 were 5'-TTACCAAGCAG CCGAAGA-3' and 5'-TCCCTCCTTTACATTCACAA-3' (309 bp, NM_ 138621); the sense and antisense primers for bax, 5'-TTTTGCTTCAGGGTTTCATC-3' and 5'-GGCCTT GAGCACCAGTTT-3' (299 bp, BC014175); the sense and antisense primers for p53, 5'-GTCTACCTCCCGCCATAA-3', 5'-CATCTCCCAAACATCCCT-3' (316 bp,NM_001126114.2); the sense and antisense primers for cyclin A, 5'-TTAGGGAAA TGGAGGTTA-3' and 5'-CAGAAAGTATTGGGTAAGAA-3' (404 bp, NM_001237.3); the sense and antisense primers for cyclin B, 5'-TCTGCTGGGTGTAGGTCC-3' and 5'-AATA GGCTCAGGCGAAAG-3' (444 bp, NM_0319 66.3); the sense and antisense primers for cyclin D1, 5'-CTGGATGCTGGAGG TCTGCGAGGA-3' and 5'-TGAACTTCACATCTGTGGCAC AGA-3' (400 bp, M 73554), respectively. The cycling conditions: $94^{\circ} \mathrm{C}$ for $5 \mathrm{~min}$, followed by 28 cycles of $94^{\circ} \mathrm{C}$ for $30 \mathrm{sec}$, $58^{\circ} \mathrm{C}$ for $30 \mathrm{sec}$ and $72^{\circ} \mathrm{C}$ for $1 \mathrm{~min}$, and a final extension of $72^{\circ} \mathrm{C}$ for $10 \mathrm{~min}$. PCR products were separated on the $1.5 \%$ agarose gel viewed by ethidium bromide staining. These data were acquired with Tocan 360 gel imager (version 3.2.1 software, Shanghai Tiancheng Technology Inc., Shanghai, China). The RT-PCR experiments were done in duplicates.

Cell cycle analysis. HepG2 cells $\left(1 \times 10^{5}\right)$ were seeded in a 6 -well plate. After 24 -h incubation at $37^{\circ} \mathrm{C}\left(5 \% \mathrm{CO}_{2}\right)$, the medium was changed with fresh, supplemented or not (control) with the Mannich base (50 and $100 \mu \mathrm{M})$. After 24-h incubation, cells were harvested with trypsin, washed by PBS, fixed in $70 \%$ ethanol and stored at $-20^{\circ} \mathrm{C}$ for $1 \mathrm{~h}$. The cellular nuclear DNA was stained by propidium iodide (PI) as described (13), briefly, followed by removing the ethanol, washed with $\mathrm{PBS}$, the cells were suspended in $0.5 \mathrm{ml} \mathrm{PBS}$ containing $50 \mu \mathrm{g} / \mathrm{ml} \mathrm{PI}$ and $100 \mu \mathrm{g} / \mathrm{ml}$ RNase and incubated at $37^{\circ} \mathrm{C}$ for $30 \mathrm{~min}$. Flow cytometry was performed in duplicate with a FACScalibur flow cytometer (Becton-Dickinson, USA). From each sample 10,000 events were collected and fluorescent signal intensity was recorded and analyzed by CellQuest and Modifit (Becton-Dickinson).

Flow cytometry analysis of mitochondrial membrane potential. Following similar procedure as mentioned in cell cycle analysis, the HepG2 cells were treated with the Mannich base (50 and $100 \mu \mathrm{M})$ or its copper complex $(6$ and $12 \mu \mathrm{M})$ for $24 \mathrm{~h}$, the cells were washed with PBS twice after removing the cell medium and digested with trypsin. Treated cells were collected and resuspended at a concentration of $1 \times 10^{5} / \mathrm{ml}$ in PBS containing $1 \mu \mathrm{mol} / 1$ rhodamine 123 and then incubated at $37^{\circ} \mathrm{C}$ for $30 \mathrm{~min}$ for direct use in flow cytometry. Samples were analyzed by FACSCalibur flow cytometer (Becton-Dickinson) with an excitation wavelength of $488 \mathrm{~nm}$ and an emission wavelength of $525 \mathrm{~nm}$. Data collection and analysis were as described above.

DNA Top activity assay. The nuclear extract from HepG2 cells was prepared as described (13). Briefly, cells were detached using trypsin followed by centrifugation and washing twice 


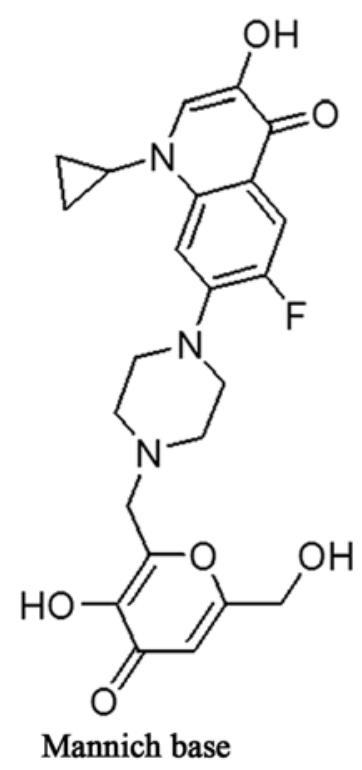

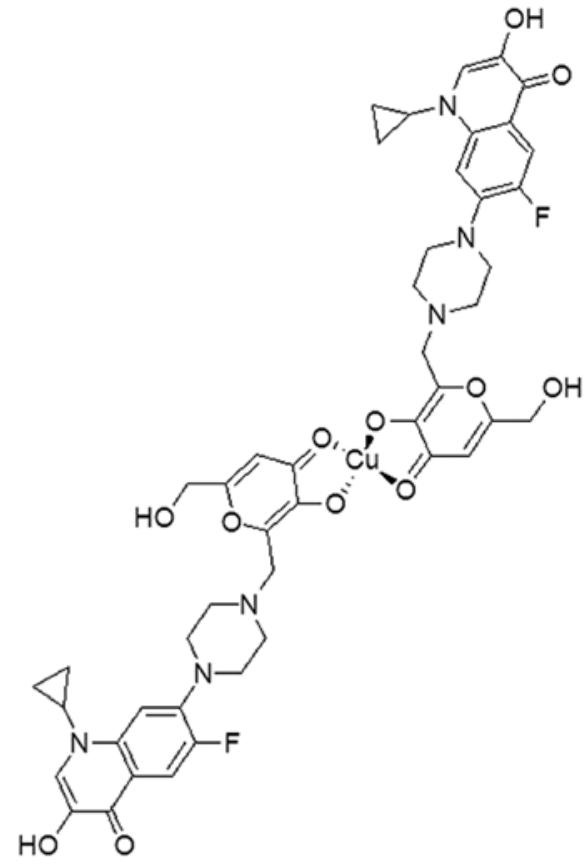

Mannich base-copper complex

Figure 1. The structures of the prepared Mannich base and its copper complex.

with cold nucleus buffer (NB) $(150 \mathrm{mM}$ sodium chloride, $1 \mathrm{mM}$ potassium dihydrogen phosphate, $5 \mathrm{mM}$ magnesium chloride, $1 \mathrm{mM}$ EDTA, $2 \mathrm{mM}$ dithiotreitol and $1 \mathrm{mM}$ PMSF, $\mathrm{pH} 6.4)$ at $4^{\circ} \mathrm{C}$. The supernatant was discarded and the cell pellet was re-suspended in $300 \mu 1 \mathrm{NB}$ with $0.3 \%$ Triton X-100 and placed on ice for $10 \mathrm{~min}$, then transferred into a glass Dounce homogenizer with ten up-and-down strokes using a loose-fitting pestle. The suspension solution was centrifuged at $150 \mathrm{x} \mathrm{g}$ for $10 \mathrm{~min}$ at $4^{\circ} \mathrm{C}$, the pellet washed with Triton $\mathrm{X}-100$-free cold NB. Cold NB solution $(150 \mu \mathrm{l})$ containing $0.35 \mathrm{M} \mathrm{NaCl}$ was added to the pellet and allowed to stand $30 \mathrm{~min}$ at $4^{\circ} \mathrm{C}$ in order to extract the nuclear proteins. The supernatant was obtained by centrifugation at $10,000 \mathrm{x} \mathrm{g}$ for $10 \mathrm{~min}$ at $4^{\circ} \mathrm{C}$. The protein concentration was determined using the Bradford method. Nuclear extract $(0.4 \mu \mathrm{g})$ was added to the Top reaction mixture containing $10 \mathrm{mM}$ Tris-HCl (pH 7.5), 1 mM EDTA, $150 \mathrm{mM} \mathrm{NaCl}, 0.1 \%$ BSA (bovine serum albumin), $0.1 \mathrm{mM}$ spermidine, $5 \%$ glycerol and $0.4 \mu \mathrm{g}$ pUC18 and $3 \mu \mathrm{l}$ (or 2 , or $1 \mu \mathrm{l}$ ) test compound ( 1 or $0.3 \mathrm{mM}$ ) at a final volume of $10 \mu \mathrm{l}$. Following incubation at $37^{\circ} \mathrm{C}$ for $30 \mathrm{~min}$, the reaction was terminated by adding $5 \mu \mathrm{l}$ of stopping buffer (10\% SDS, $0.025 \%$ bromophenol blue and $5 \%$ glycerol). The reaction products were analyzed by electrophoresis on $1 \%$ agarose gel using a TBE buffer with $0.1 \%$ SDS ( $89 \mathrm{mM}$ Tris-HCl, $89 \mathrm{mM}$ boric acid and $62 \mathrm{mM}$ EDTA) at $45 \mathrm{~V}$ for $3 \mathrm{~h}$, stained by ethidium bromide $(0.5 \mu \mathrm{g} / \mathrm{ml})$ and photographed using a short wavelength UV lamp on Tocan 360 gel scanner (Shanghai Tiancheng Technology Inc.). The assay was conducted in duplicate.

Molecular docking studies. The structure of human type I DNA Top with DNA and Topotecan $(1 \mathrm{~K} 4 \mathrm{~T})$ and human type II Top (3QX3) were obtained from RCSB Protein
Data Bank (20). The Mannich base was generated from Chemdraw (Chemdraw Ultra 8.0, CambridgeSoft, USA). Similarly structure of its copper complex was proposed based on copper (II) ion coordination geometry in general. The energy minimization was conducted by Chem3D (Ultra 8.0, CambridgeSoft) (21). The resulting models were displayed in PyMol (The PyMOL Molecular Graphics System, Version 1.4.1, Schrödinger, LLC, USA).

Molecular docking studies were performed by AutoDock Vina and AutoDock Tools based on the recommended procedure (22). Grid boxes were set to the center of ciprofloxacin (or topotecan) model, and the grid box size for Mannich base models was set to 22,24 , and 28 for $\mathrm{x}$-, $\mathrm{y}$ - and $\mathrm{z}$-axis, respectively. The Mannich base was set as a flexible ligand by using the default parameters of the AutoDock Tools. The optimal conformation of the ligand was generated by AutoDock Vina.

\section{Results}

Antitumor activity. It has been demonstrated that ciprofloxacin and kojic acid exhibit their cytotoxicity against some tumor cell lines. The Mannich base containing ciprofloxacin structural unit might have similar property. To determine their potential antitumor activity, the proliferation inhibition of the Mannich base against HepG2 and HCT-116 cell lines was investigated by MTT assay (Fig. 2). For both cell lines, the Mannich base was shown to be more toxic than ciprofloxacin, with $\mathrm{IC}_{50}=103.3 \pm 5.1 \mu \mathrm{M}$ for HepG2, and 87.9 $\pm 8.0 \mu \mathrm{M}$ for HCT-116, respectively (Fig. 2). Due to copper chelator ability of kojic acid, the copper complex of the Mannich base was prepared and evaluated. It is notable that the copper complex exhibited excellent biological activities and selectivity, indicating there is a synergistic effect when the copper ion was 

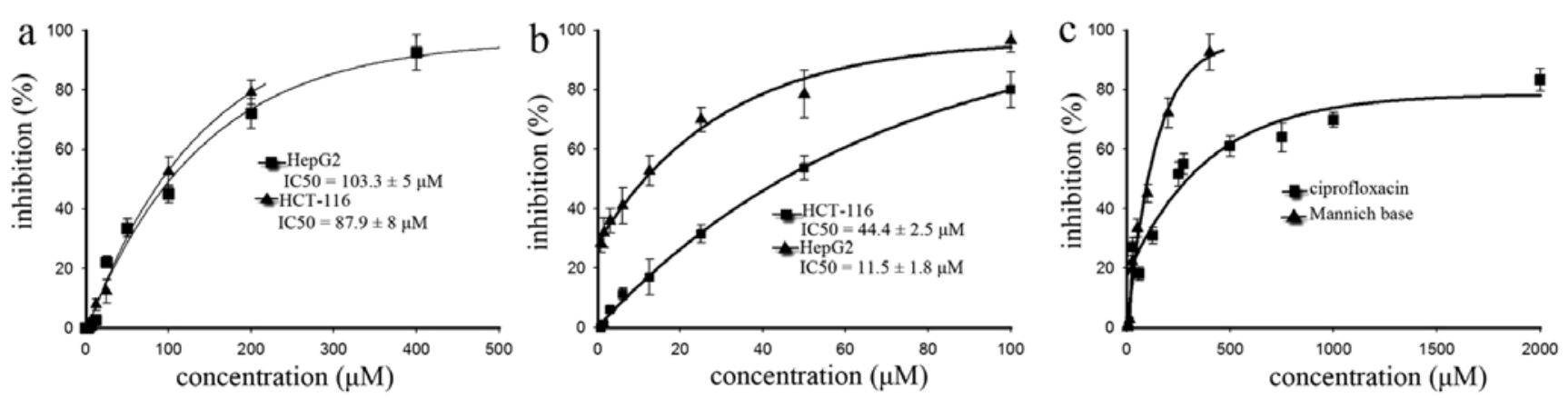

Figure 2. Antitumor activities of Mannich base and its copper complex of kojic acid with ciprofloxacin against HepG2 and HCT-116 cell lines. (a) Proliferation inhibition of the Mannich base. (b) Proliferation inhibition of the copper complex with Mannich base; the copper complex was prepared by mixing equivalently the Mannich and copper chloride, the precipitate was dissolved in DMSO with the same volume as that before mixing. (c) Comparison of the Mannich base with ciprofloxacin in proliferation inhibition of the HepG2 cell line.
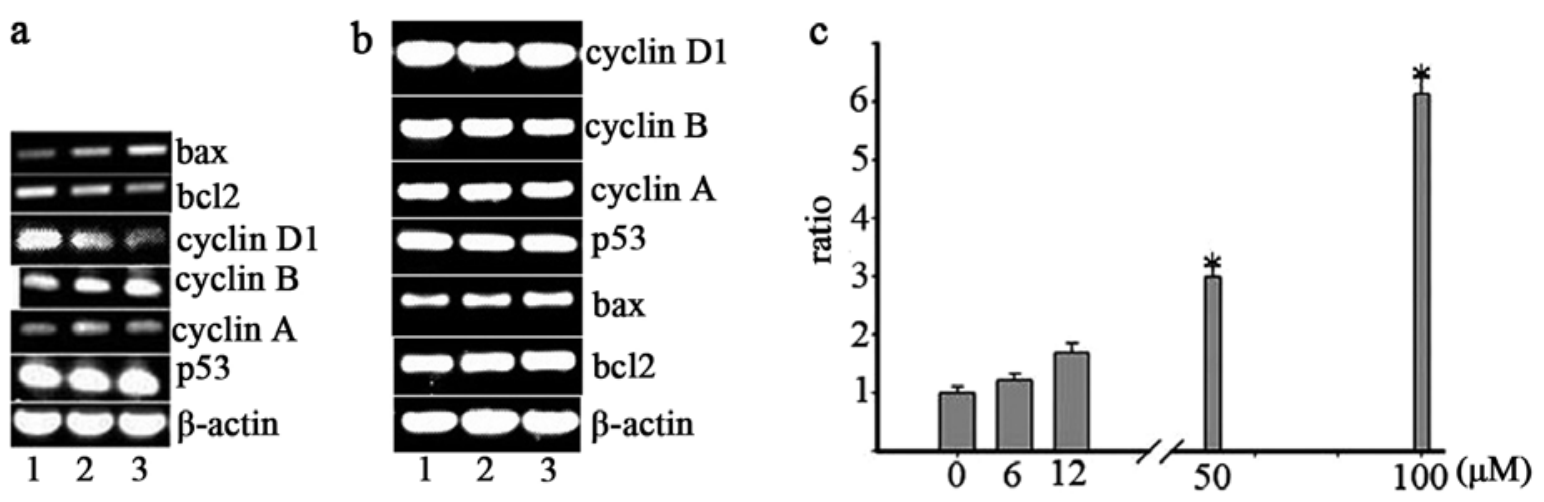

Figure 3. The regulation of Mannich base and its copper complex on apoptotic and cell cycle related genes. (a) Gene regulation of Mannich base. 1, Control; 2, Mannich base $(50 \mu \mathrm{M}) ; 3$, Mannich base $(100 \mu \mathrm{M})$. (b) Gene regulation of Mannich base-copper complex. 1, Control; 2, Mannich base (6 $\mu \mathrm{M}) ; 3$, Mannich base $(100 \mu \mathrm{M})$. (c) Normalized ratio of bax/bcl2 at 0, 6 (copper complex), 12 (copper complex), 50 and $100 \mu \mathrm{M}$ the investigated compounds. "p $<0.05$.

chelated by the Mannich base. The $\mathrm{IC}_{50}$ of the copper complex was $11.5 \pm 3.0 \mu \mathrm{M}$ for HepG2 cell, a $\sim 10$-fold decrease in $\mathrm{IC}_{50}$ compared to that of the Mannich base. Similar trend against HCT-116 cell line was also observed, except the 2-fold dropped $\mathrm{IC}_{50}$ (87 vs $44 \mu \mathrm{M}$ in $\mathrm{IC}_{50}$ ). The copper complex seemed to exhibit to some extent selectivity for HepG2 cell.

The regulation of the Mannich base and its copper complex on apoptotic gene expression. The Mannich base and its copper complex showed good antitumor activities, it was necessary to determine their action mechanism. Ciprofloxacin induces apoptosis via regulation of pro-apoptotic Bax, anti-apoptotic Bcl-2 genes to exert its cytotoxicity, so RT-PCR was employed to evaluate the gene regulation of the Mannich base and its copper complex. As shown in Fig. 3a, Bax increased dosedependently after $24 \mathrm{~h}$ of incubation of the Mannich base, while $\mathrm{Bcl}-2$ was decreased. For easy comparison, the ratio of $\mathrm{Bax} / \mathrm{Bcl}-2$ was set at 1.0 in untreated cells, and the changes are shown in Fig. 3c (narrow bar). It was clear that the Bax/ Bcl-2 ratio in the Mannich base treated cells was significantly increased in a concentration-dependent manner, indicating that the cytotoxicity of the investigated compounds might be involved in apoptosis. The cell cycle factor was also checked, it is of interest that the cyclin D1 was downregulated, which was correlated to G1 arrest. However, other cell cycle factors and p53 were not clearly changed (Fig. 3a). Similar procedure was applied on the gene regulation of the copper complex (Fig. 3b), the investigated gene expression was not significantly changed except the Bax slight increased, showing that a different way occurred compared to the Mannich base.

Cell cycle arrest. The proliferation inhibition may stem from disturbing the cell cycle, to test the hypothesis, cell cycle analyses were conducted after 24-h exposure of the drugs to HepG2 cells under $\mathrm{IC}_{50}$. As shown in Fig. 4a-c, the Mannich base caused an accumulation of cells in the G1-phase. The percentage of cells at the G1-phase significantly increased from 58.43 to 76.14 and $70.67 \%$ after treatment with 50 and $100 \mu \mathrm{M}$ Mannich base, respectively. The result indicated that the anti-proliferative effect of the Mannich base could be partly derived from inducing cell cycle arrest. When the cells were treated with the copper complex, the G1 arrest was not observed (Fig. 4d-f), indicating that the cytotoxicity of the copper complex was not due to the disturbance of cell cycle.

Mitochondrial membrane potential. Ciprofloxacin can depolarize the mitochondrial membrane and inhibit mtDNA synthesis, so it was necessary to determine whether the Mannich base and its copper complex has similar function. The depolarization of mitochondrial membrane was evalu- 

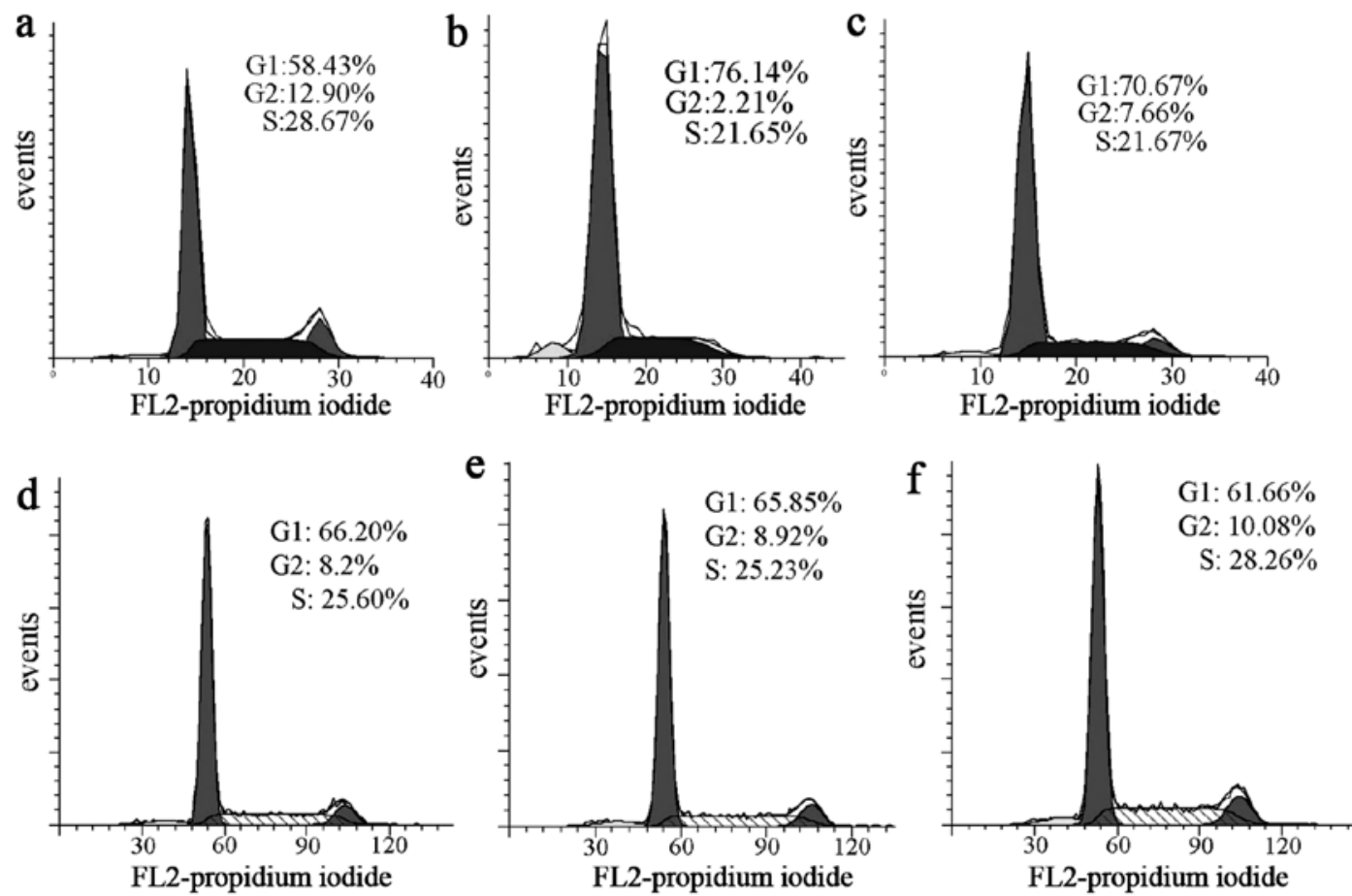

Figure 4. Cell cycle arrest by the Mannich base. (a) Control. (b) In the presence of $50 \mu \mathrm{M}$ Mannich base. (c) In the presence of $100 \mu \mathrm{M}$ Mannich base (d) Control (0.5\% DMSO). (e) Copper complex (6 $\mu \mathrm{M})$. (f) Copper complex (12 $\mu \mathrm{M})$.
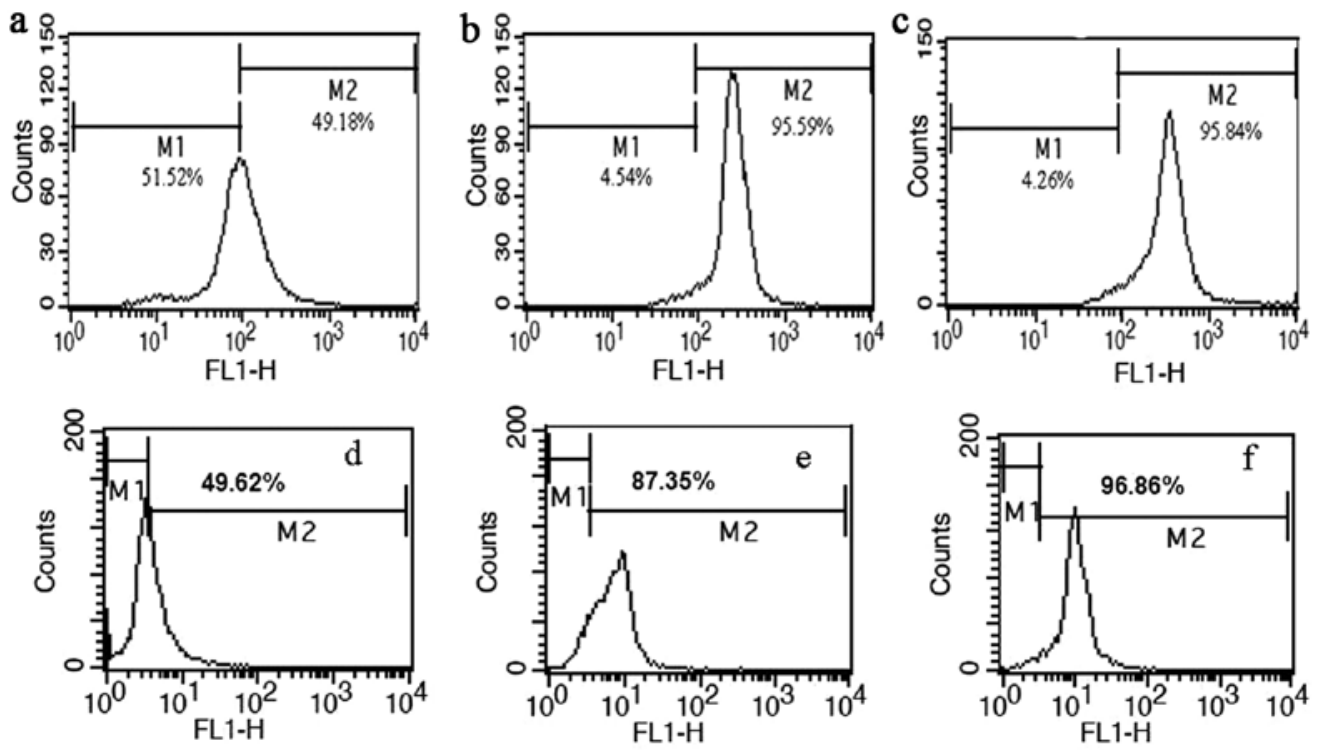

Figure 5. The effect of the Mannich base on mitochondrial membrane permeability. (a) Control. (b) Mannich base (50 $\mu \mathrm{M})$. (c) Mannich base (100 $\mu \mathrm{M})$. (d) Control (0.5\% DMSO). (e) Copper complex $(6 \mu \mathrm{M})$. (f) Copper complex $(12 \mu \mathrm{M})$.

ated via rhodamine 123 staining on BD flow cytometry. The results are shown in Fig. 5. Compared to control, the distribution of cells with different fluorescence was significantly altered both for the Mannich base and its copper complex treated groups. Almost all the cells (87-95\%) were in M2 gate after the drugs treatments, a $\sim 38-46 \%$ increase could be seen (Fig. 5). These observations indicated that both the Mannich base and its copper complex could depolarize the mitochondrial membrane, decreasing its electrochemical potential.
Inhibition of DNA human Top. Ciprofloxacin as a type II DNA Top inhibitor is well documented. To determine whether the Mannich base and its copper complex recapitulate such activity, plasmid DNA was incubated with nucleic extract in the presence of a varied concentration of the investigated compounds, and reaction products were analyzed by gel electrophoresis. As shown in Fig. 6a, the Mannich base exhibited inhibition of human Top II (at $300 \mu \mathrm{M}$ ), but the Top I inhibition was not observed. The copper complex exhibited dual Top inhibition both for type I and II at much 
a

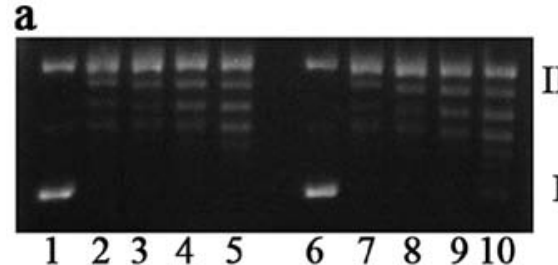

b

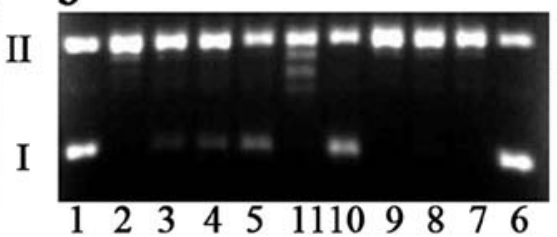

C

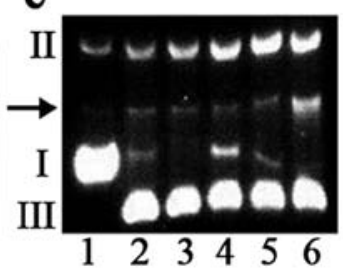

Figure 6. The topoisomerase inhibition of Mannich base and its copper complex. I, supercoiled; II, cleaved DNA; and III, relaxed DNA. (a) 1 and 6, pUC18 only; 2, pUC18 + nucleic extract; 3-5, pUC18 + nucleic extract in the presence of 200, 400 and $600 \mu \mathrm{M}$ Mannich base without ATP; 7 , pUC18 + nucleic extract with ATP; 8-10, pUC18 + nucleic extract in the presence of 200, 400 and $600 \mu \mathrm{M}$ Mannich base with ATP. (b) 1 and 6 , pUC18 only; $2-4$, pUC18 + nucleic extract in the presence of 30,60 and $90 \mu \mathrm{M}$ Mannich base copper complex without ATP; 7, pUC18 + nucleic extract with ATP; 8-10, pUC18 + nucleic extract in the presence of 30,60 and $90 \mu \mathrm{M}$ Mannich base copper complex with ATP; 11 , pUC18 + nucleic extract in the presence of $300 \mu \mathrm{M}$ ciprofloxacin. (c) 1 , pUC18; 2 , pUC18 + nucleic extract; 3-5, pUC18 + nucleic extract in the presence of 30, 60 and $90 \mu \mathrm{M}$ Mannich base copper complex with ATP; 6, pUC18 + nucleic extract $+3 \mathrm{mM}$ etoposide; arrow, potent DNA-topoisomerase complex.

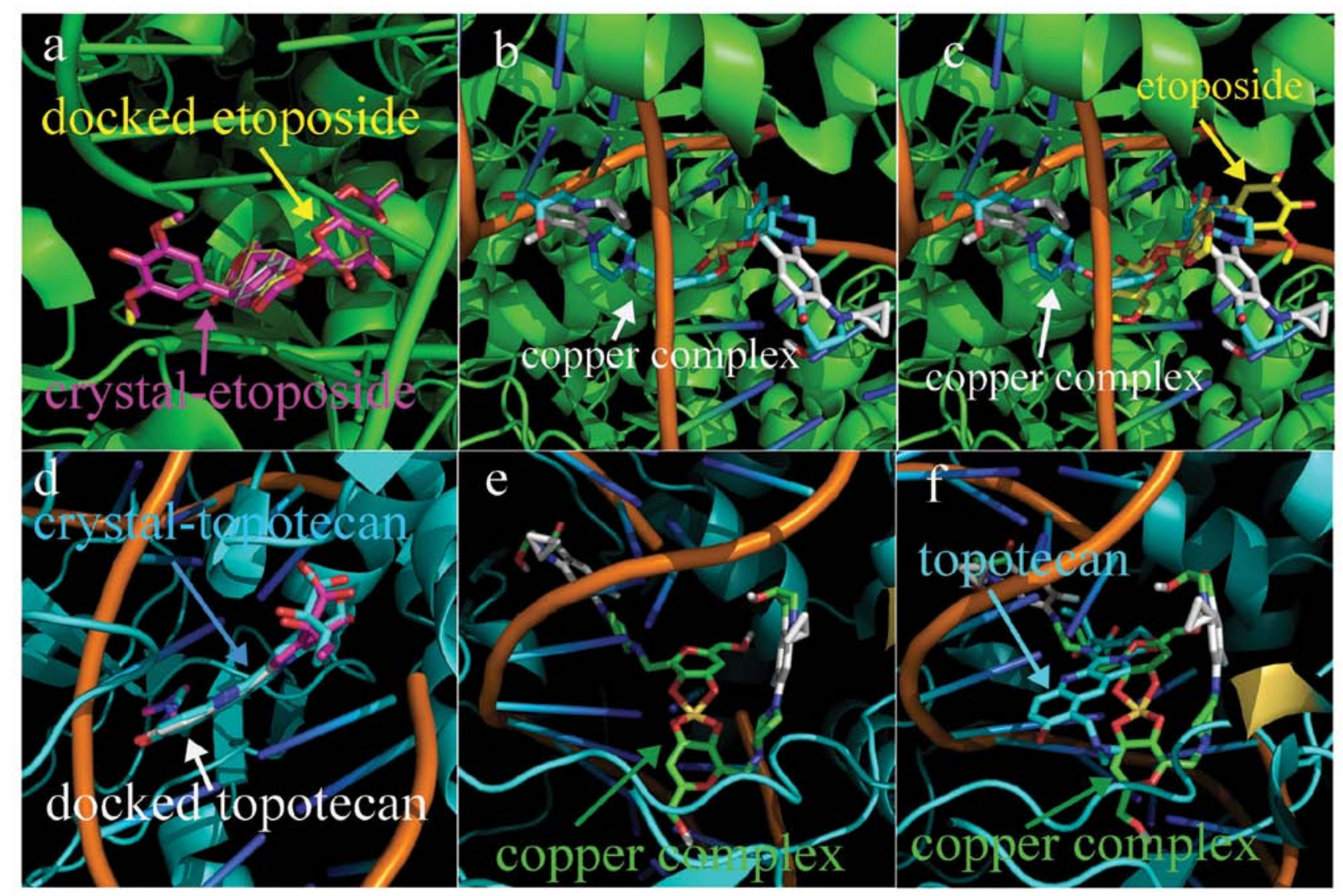

Figure 7. The docked copper complex of the Mannich base in topoisomerase. (a) Superimposition of docked etoposide on the crystallized etoposide in the cleavage DNA complex. (b) Copper complex in the cleavage DNA complex. (c) Comparison of the copper complex with etoposide at the cleavage site. (d) Superimposition of docked topotecan on the crystallized topotecan in the cleavage DNA complex. (e) Copper complex in the cleavage DNA complex. (f) Comparison of the copper complex with topotecan at the cleavage site.

lower concentration (Fig. 6b). To further reveal the action mode of the copper complex in Top inhibition, the reaction mixtures were subjected to electrophoresis on EtB containing agarose gel. As shown in the gel (Fig. 6c), the topology was dominated by the intercalative dye, all closed circular forms of DNA would be positively supercoiled and migrate with similar rate. The Top II cleavage complex could be identified by comparison with the positive control of etoposide. From Fig. 6c, the Top II-DNA cleavage complex was seen and the amount of cleavage DNA was increased with increasing of the concentration of the copper complex, indicating that the potent cytotoxicity of the copper complex may contribute to stabilize the Top II-DNA cleavage complex.

Molecular docking analysis. Top inhibition exerted by the copper complex in vitro made us look for potent structural basis, the molecular docking was conducted. The human type I and II Top crystal structures were from RCSB Protein Data Bank. In order to evaluate the accuracy of our docking protocol, etoposide and topotecan were re-docked into each Top-DNA complex based on their crystal structures. The human type I (PDB ID:1K4T) and II Top (PDB ID:3QX3) 
were chosen as receptors, and the copper complex was used as ligand. The input pbdqt files were generated by Autodocktool and the optimal conformations of ligands were calculated on AutoDock Vina. The Top-inhibitor complex derived from docking simulation showed that the docked etoposide and topotecan were almost fully superimposed on the native co-crystallized ones (Fig. 7a and d). Following the same protocol the copper complex was individually docked into the Top I and II, the simulating affinity energy was -11.5 and $-10.9 \mathrm{kcal} / \mathrm{mol}$, respectively. Compared to that of redocked etoposide, -14.6 and topotecan, $-11.2 \mathrm{kcal} / \mathrm{mol}$, the affinity energy of the copper complex with the Top was quite close to the clinically used drugs. The orientation of the copper complex in the Top I and II is shown in Fig. 7b and e, respectively. In addition, the superimposition of the copper complex on the co-crystallized etoposide and topotecan are presented in Fig. 7c and $\mathrm{f}$.

\section{Discussion}

Ciprofloxacin has a certain degree of antitumor activity (23), so does the ciprofloxacin containing Mannich base. The proliferation inhibition of the Mannich base clearly showed that the structural modification on 7-piperdinyl ciprofloxacin with kojic acid unit leads to enhancement in antitumor activity. However, its antimicrobial activities was decreased from that reported recently (16). It should be realized that ciprofloxacin and kojic acid both have potential chelating ability, and the derivatives of kojic acid have been synthesized as a copper chelator, corresponding metal complexes of the derivatives have also been investigated $(24,25)$. The excellent proliferation inhibition of the copper complex encouraged us to probe the potent molecular mechanism. A previous study showed that the copper chloride has no detectable cytotoxicity at $50 \mu \mathrm{M}$ (data not shown), so the enhancement of the copper complex of the Mannich base in proliferation inhibition could not be simply explained as synergistic effect because synchronous exposure of the copper chloride and the Mannich base to the investigated cell lines did not induce higher cytotoxicity (data not shown). However, after adjusting the $\mathrm{pH}$ of Mannich base with base, a copper chloride addition leads to a suspension with color change, indicating the copper complex of the Mannich base was formed (26). Thus additional studies are required to probe potent molecular mechanism, which may provide some meaningful information to explain the phenomenon. It has been well demonstrated that many chemotherapeutic agents exert their cytotoxicity via apoptotic path. Bax and Bcl-2 are apoptosis-related genes, the Bax upregulation and $\mathrm{Bcl}-2$ downregulation are indicative of apoptosis involved. In our study the RT-PCR data clearly show that the Bax/Bcl-2 ratio in the Mannich base treated HepG2 cells was significantly increased, indicating that the Mannich base induced apoptosis via the same molecular path as ciprofloxacin. However, this situation for its copper complex was not observed, indicating the cytotoxicity of the copper complex might not be involved in apoptotic pathway.

It has been demonstrated that quinolone derivatives induce cell death through causing double-stranded DNA breakage, inhibition of Top function $(27,28)$, so the ciprofloxacin containing Mannich base in this study might share a similar action mechanism. To test the hypothesis Top inhibition assay was carried out. Unsurprisingly, type II topoisomerase inhibition by the Mannich base was observed at higher concentration, but the type I Top inhibition was not evident. Beyond our expectations, the copper complex exhibited dual Top inhibition, this situation has been only found in a few metal complexes (29-32), so we speculated that the excellent antitumor activity may be closely related to its dual Top inhibition. However, due to lack of evidence from crystal structure, how this kind of metal complex interacts with Top, via competitive ATP binding or poisoning DNA complex or allosteric effect to disturb unwinding DNA helix are largely unknown. In our experiment, the DNA-Top complex poisoning function of the copper complex could be seen, stabilizing the intermediate and causing more DNA cleavage in a concentration-dependent manner. As mentioned above due to lack of detailed structural information, in silico study to simulate the potent interaction between the copper complex and the DNA-Top complex may give some helpful information. Molecular docking is a well established computational technique to predict the interaction between enzyme and inhibitor $(33,34)$. In addition, AutoDock software is widely used to predict the binding information of test compounds $(35,36)$. In general, divalence copper ion (II) can be chelated by many compounds contained heteroatom, such as kojic acid, forming square planar molecules in geometry (37). So 1:2 molar ratio of copper ion to the Mannich base may be speculated, and a square planar geometry for the copper complex was tentatively proposed for the docking study. In addition, in this case, the copper complex may have non-electrolyte property and thus can easily cross the cellular membrane. It is interesting that the docked copper complex has affinity energy with the Top I or II quite close to that of etoposide or topotecan used in clinic, indicating the copper complex might have similar manner as poison to stabilize the cleavage DNA-Top complex and cause DNA fragmentation. The data from molecular docking was supportive of the Top inhibition experiment in vitro and corelated with assessment of the cytotoxicity of the complex.

Top II $\alpha$ inhibition or poisoning leads G2/M-phase arrest in general $(38,39)$, to look for further support, the cell cycle was assessed in the presence of the investigated compounds. Surprisingly, both the Mannich base and its copper complex did not lead to G2/M-phase arrest. It unambiguously demonstrated that the Mannich base caused a G1-phase arrest. Cyclin D1 plays an important role in regulating cell cycle progression and cyclin D1 degradation is sufficient to induce G1 cell cycle arrest (38). The cyclin D1 downregulation at mRNA level in the treatment of Mannich base might be also correlated with the G1 arrest. This situation was also found in Top inhibitors, for the cell cycle arrest dose-dependently in some cell lines $(40,41)$. Unlike the Mannich base, its copper complex was not able to disturb the cell cycle, indicating that the mechanisms between them were different.

Mitochondria are producing energy plants, and the ATP was produced by utilizing the proton electrochemical gradient potential between inner and outer mitochondrial membrane. The depolarization of mitochondrial membrane will result in decreases of the potential and proton gradient, consequently leading to less efficient ATP production (42). Our observations 
also support that both the Mannich base and its copper complex have functions of depolarization of mitochondrial membrane compared to the untreated group from the fluorescence intensity of mitochondria stained by rhodamine 123 (Fig. 6), which cause ATP shortage, consequently slowing down cell growth. So it is reasonable to speculate that the disturbance of mitochondrial respiration and ATP synthesis may contribute to the cytotoxic effect of the Mannich or its copper complex (43).

In conclusion, the Mannich base derived from ciprofloxacin is more toxic than its parent compound in antitumor activity. Its copper complex showed excellent antitumor activity. Mechanistic studies revealed preliminarily that the Mannich base exerted cytotoxicity via regulation of a pro-apoptotic gene, causing cell cycle arrest, disturbing ATP production and inhibiting Top II. Unlike the Mannich base, the cytotoxicity of its copper complex mainly stem from its ability to stabilize the intermediate of cleavage DNA-Top complex as well as disturbance of the mitochondrial respiration chain. However, detailed mechanism of the copper complex, especially in Top inhibition in vivo is largely unknown and require more study in the future.

\section{Acknowledgements}

This study was supported by grants CP1204 from Xinxiang Scientific and Technology Division; ZD2011-06 from Xinxiang Medical University and 2109901 from plan of Health Scientific and Technological Innovation Talents of Henan Province for Shaoshan Li.

\section{References}

1. Bentley R: From miso, sake and shoyu to cosmetics: a century of science for kojic acid. Nat Prod Rep 23: 1046-1062, 2006

2. Noh JM, Kwak SY, Kim DH, et al: Kojic acid-tripeptide amide as a new tyrosinase inhibitor. Biopolymers 88: 300-307, 2007

3. Aytemir MD and Özçelik B: A study of cytotoxicity of novel chlorokojic acid derivatives with their antimicrobial and antiviral activities. Eur J Med Chem 45: 4089-4095, 2010.

4. Xiong $X$ and Pirrung MC: Modular synthesis of candidate indole-based insulin mimics by Claisen rearrangement. Org Lett 10: 1151-1154, 2008

5. Kasser, JH, Kandioller, W, Hartinger, CG, et al: Mannich products of kojic acid and N-heterocycles and their $\mathrm{Ru}(\mathrm{II})$ - arene complexes: synthesis, characterization and stability. J Organomet Chem 695: 875-881, 2010.

6. Toy AD and Smith TD: Electron spin resonance evidence for the existence of a dimeric form of the copper (II) chelate of kojic acid. J Am Chem Soc 93: 3049-3050, 1971.

7. Yoo JY, Pradarelli J, Haseley A, et al: Copper chelation enhances antitumor efficacy and systemic delivery of oncolytic HSV. Clin Cancer Res 18: 4931-4941, 2012.

8. Chen YH, Lu PJ, Hulme C, et al: Synthesis of kojic acid-derived copper-chelating apoptosis inducing agents. Med Chem Res 22: 995-1003, 2013.

9. Fickova M, Pravodova E, Rondhal L, et al: In vitro antiproliferative and cytotoxic activities of novel kojic acid derivatives: 5-benzyloxy-2-selenocyanatomethyl- and 5-methoxy-2-selenocyanatomethyl-4-pyranone. J Appl Toxicol 28: 554-559, 2008.

10. Yoo DS, Lee J, Choi SS, et al: A modulatory effect of novel kojic acid derivatives on cancer cell proliferation and macrophage activation. Pharmazie 65: 261-266, 2010.

11. Hawtin RE, Stockett DE, Byl JAW, et al: Voreloxin is an anticancer quinolone derivative that intercalates DNA and poisons topoisomerase II. PLoS One 5: e10186, 2010.

12. Seo KW, Holt R, Jung YS, et al: Fluoroquinolone-mediated inhibition of cell growth, S-G2/M cell cycle arrest, and apoptosis in canine osteosarcoma cell lines. PLoS One 7: e42960, 2012.
13. Fu Y, Zhang Y, Zhou SF, et al: The effects of substitution of carboxyl with hydrazide group on position 3 of ciprofloxacin on its antimicrobial and antitumor activity. Int J Pharmacol 9: 416-429, 2013

14. Ahmed A and Daneshtalab M: Nonclassical biological activities of quinolone derivatives. J Pharm Pharmaceut Sci 15: 52-72, 2012.

15. Yadav P and Joshi YC: Syntheses and spectral studies of novel ciprofloxacin derivatives. Bull Chem Soc Ethiop 22: 459-464, 2008.

16. Emami S, Ghafouri E, Faramarzi MA, et al: Mannich bases of 7-piperazinylquinolones and kojic acid derivatives: synthesis, in vitro antibacterial activity and in silico study. Eur J Med Chem 68: 185-191, 2013.

17. Jubie S, Sikdar P, Kalirajan R, et al: Synthesis and antimicrobial activity of some novel ciprofloxacin analogues. J Pharm Res 3: 511-513, 2010.

18. Alipour E, Mohammadhosseini N, Panah F, et al: Synthesis and in vitro cytotoxic activity of N-2-(2-Furyl)-2-(chlorobenzyloxyimino) ethyl ciprofloxacin derivatives. E-J Chem 8: 1226-1231, 2011

19. Cormiera R, Burdab WN, Harringtonb L, et al: Studies on the antimicrobial properties of $\mathrm{N}$-acylated ciprofloxacins. Bioorg Med Chem Lett 22: 6513-6520, 2012.

20. Bax BD, Chan PF, Eggleston DS, et al: Type IIa topoisomerase inhibition by a new class of antibacterial agents. Nature 466: 935-940, 2010.

21. Ok K, Jung YW, Jee JG, et al: Facile docking and scoring studies of carborane ligands with estrogen receptor. Bull Korean Chem Soc 34: 1051-1054, 2013.

22. Trott $\mathrm{O}$ and Olson AJ: AutoDock Vina: improving the speed and accuracy of docking with a new scoring function, efficient optimization and multithreading. J Comput Chem 31: 455-461, 2010.

23. Bourikas LA, Kolios G, Valatas V, et al: Ciprofloxacin decreases survival in HT-29 cells via the induction of TGF- $\beta 1$ secretion and enhances the anti-proliferative effect of 5-fluorouracil. Br J Pharmacol 157: 362-370, 2009.

24. Kwak SY, Choi HR, Park KC, et al: Kojic acid-amino acid amide metal complexes and their melanogenesis inhibitory activities. J Pept Sci 17: 791-797, 2011

25. Kwak SY, Noh JM, Park SH, et al: Enhanced cell permeability of kojic acid-phenylalanine amide with metal complex. Bioorg Med Chem Lett 20: 738-741, 2010.

26. Kenyon GD, Chen Di, Shirley O, et al: Clioquinol and pyrrolidine dithiocarbamate complex with copper to form proteasome inhibitors and apoptosis inducers in human breast cancer cells. Breast Cancer Res 7: R897-R908, 2005.

27. Drlica K, Malik M, Kerns RJ and Zhao X: Quinolone-mediated bacterial death. Antimicrob Agents Chemother 52: 385-392, 2008.

28. Sun JP, Shi ZY, Liu SM, et al: Trimethoxy-benzaldehyde levofloxacin hydrazone inducing the growth arrest and apoptosis of human hepatocarcinoma cells. Cancer Cell Int 13: 67, 2013.

29. Ahmad M, Afzal M, Tabassum S, et al: Synthesis and structure elucidation of a cobalt(II) complex as topoisomerase I inhibitor: in vitro DNA binding, nuclease and RBC hemolysis. Eur J Med Chem 74: 683-693, 2014.

30. Kou JF, Qian C, Wang JQ, et al: Chiral ruthenium(II) anthraquinone complexes as dual inhibitors of topoisomerases I and II. J Biol Inorg Chem 17: 81-96, 2012.

31. Patel MN, Bhatt BS and Dosi PA: Topoisomerase inhibition, nucleolytic and electrolytic contribution on DNA binding activity exerted by biological active analogue of coordination compounds. Appl Biochem Biotechnol 166: 1949-1968, 2012.

32. Castelli S, Vassallo O, Katkar P, et al: Inhibition of human DNA topoisomerase IB by a cyclometalated gold III compound: analysis on the different steps of the enzyme catalytic cycle. Arch Biochem Biophys 516: 108-112, 2011.

33. Huang B: MetaPocket: a meta approach to improve protein ligand binding site prediction. Omics 13: 325-330, 2009.

34. Fukunishi $\mathrm{Y}$ and Nakamura $\mathrm{H}$ : Prediction of ligand-binding sites of proteins by molecular docking calculation for a random ligand library. Protein Sci 20: 95-106, 2011.

35. Nikaido H and Pagès JM: Broad specificity efflux pumps and their role in multidrug resistance of Gram negative bacteria. FEMS Microbiol Rev 36: 340-363, 2012.

36. Takatsuka Y, Chen $\mathrm{C}$ and Nikaido H: Mechanism of recognition of compounds of diverse structures by the multidrug efflux pump AcrB of Escherichia coli. Proc Natl Acad Sci USA 107: 6559-6565, 2010. 
37. Singh S, Singh J, Gulia S, et al: Metal ion selectivity of kojate complexes: a theoretical study. J Theor Chem 2013: 342783, 2013.

38. Guo L, Liu XJ, Nishikawa K, et al: Inhibition of topoisomerase IIA and G2 cell cycle arrest by NK314, a novel benzo[c] phenanthridine currently in clinical trials. Mol Cancer Ther 6: 1501-1508, 2007.

39. Masamha CP and Benbrook DM: Cyclin D1 degradation is sufficient to induce G1 cell cycle arrest despite constitutive expression of cyclin E2 in ovarian cancer cells. Cancer Res 69: 6565-6572, 2009.

40. Li TM, Chen GW, Su CC, et al: Ellagic acid induced p53/p21 expression, G1 arrest and apoptosis in human bladder cancer T24 cells. Anticancer Res 25: 971-980, 2005.
41. Stravopodis DJ, Karkoulis PK, Konstantakou EG, et al: Gradedependent effects on cell cycle progression and apoptosis in response to doxorubicin in human bladder cancer cell lines. Int J Oncol 34: 137-160, 2009.

42. Perry SW, Norman JP, Barbieri J, et al: Mitochondrial membrane potential probes and the proton gradient: a practical usage guide. Biotechniques 50: 98-115, 2011.

43. Rawi SM, Mourad IM, Arafa NMS, et al: Effect of ciprofloxacin and levofloxacin on some oxidative stress parameters in brain regions of male albino rats. Afr J Pharm Pharmacol 5: 1888-1897, 2011. 